\title{
Fecundity and sexual size dimorphism of wolf spiders (Araneae: Lycosidae) along an elevational gradient in the Arctic
}

\author{
Joseph J. Bowden • Toke T. Høye • \\ Christopher M. Buddle
}

Received: 24 October 2012/Revised: 7 February 2013/ Accepted: 13 February 2013

(c) Springer-Verlag Berlin Heidelberg 2013

\begin{abstract}
Fecundity and body size are central fitnessrelated traits, and their intra-specific responses to environmental variation are receiving increasing attention in the context of climate change. Recent results from Greenland indicate that temporal and spatial variation in body size differences between sexes (sexual size dimorphism) may be widespread among wolf spider species and could be related to climate. Here, we tested whether variation in elevation affected body size of three wolf spider (Araneae: Lycosidae) species in low-Arctic Canada, whether the sexes differed in their response to the cline, and whether changes in local density influenced this
\end{abstract}

Electronic supplementary material The online version of this article (doi:10.1007/s00300-013-1308-6) contains supplementary material, which is available to authorized users.

J. J. Bowden $(\square)$

Division of Biological Sciences, University of California

San Diego, 9500 Gilman Drive, No. 0116, La Jolla,

CA 92093-0116, USA

e-mail: joey.bowden@gmail.com

T. T. Høye

Department of Bioscience, Aarhus University,

Grenåvej 14, 8410 Rønde, Denmark

T. T. Høye

Arctic Research Centre, Aarhus University,

8000 Aarhus C, Denmark

T. T. Høye

Ecoinformatics and Biodiversity Group, Department

of Bioscience, 8000 Aarhus C, Denmark

C. M. Buddle

Department of Natural Resource Sciences, McGill University, Macdonald Campus, 21,111 Lakeshore Road, Sainte Anne de Bellevue, QC H9X 3V9, Canada relationship. We also tested whether fecundity changed with elevation in two of the species, independent of body size variation. We found a significant sex-elevation interaction for Pardosa lapponica: female size decreased more in response to elevation than that of males. Males and females of Pardosa uintana decreased significantly in size with elevation at a similar rate. Alopecosa aculeata males increased in body size along the gradient while females did not. Pardosa lapponica females, but not $P$. uintana females, showed significant reduction in fecundity in response to elevation. $P$. uintana showed significant decreases in body size with increases in its population density. Changes in temperature and potential resource availability along the elevational gradient are probably causing these species- and sex-specific responses. Further summer warming of the region may alleviate current constraints on growth and reproduction of these species although sex-specific responses may affect their population dynamics.

Keywords Altitudinal gradient · Yukon Territory · Pardosa $\cdot$ Alopecosa $\cdot$ Body size

\section{Introduction}

The Arctic is experiencing climate warming at a disproportionate rate relative to other parts of the world (Hansen et al. 2006), and the life histories of Arctic fauna have been changing in response to recent climate change (Høye et al. 2007; Post et al. 2009). Arctic terrestrial arthropods are predicted to be affected significantly and rapidly by global climate changes (Callaghan et al. 2004), but the scarcity of data from the region has limited such assessments to a few local sites (e.g., Høye and Forchhammer 2008; Tulp and 
Schekkerman 2008). Fecundity and body size are central fitness-related traits in arthropods, and their intra-specific responses to environmental variation are receiving increasing attention in the context of climate change (Stillwell et al. 2010). For instance, males and females are subject to different selection pressures and may therefore be differentially affected by climatic variation (e.g., Høye et al. 2009). Recent results indicate significant temporal (years) and spatial (elevation) variation in body size differences between sexes, termed sexual size dimorphism (SSD) in wolf spider species in Greenland (Høye et al. 2009; Høye and Hammel 2010). This phenomenon may be widespread among wolf spider species in the Arctic.

Body size differences between the sexes occur frequently in nature with males generally being larger in the endotherms and females being larger in ectotherms (Fairbairn 2007). Differences in SSD have been detected among populations within species, and the direction and strength of SSD can be influenced by geographic variation (Blanckenhorn and Demont 2004; Schäuble 2004; Stillwell et al. 2007) or vary in response to changes in biotic or abiotic factors (Foellmer and Moya-Laraño 2007; Stillwell et al. 2010). Sex-specific responses to various environmental drivers can arise through sex-differences in phenotypic plasticity or genetic makeup (Stillwell and Fox 2007; Stillwell and Fox 2009). Variation in SSD over geographic clines has been detected in some groups, primarily at temperate and tropical latitudes (e.g., Schäuble 2004; Blanckenhorn et al. 2006; but see Høye and Hammel 2010).

Strong environmental and spatial gradients represent ideal model systems for studying variation in life history traits. Along such gradients, environmental variation can reveal the potential range of life history variation in a given species. Spatial gradients can be considered as gradients in resource availability and season length (variability in climate) reflecting, e.g., the harshness of local climate with increasing elevation (e.g., Hodkinson 2005). Changes across elevation have yielded significant changes in life history characteristics (e.g., body size, fecundity, and phenology) of terrestrial arthropods such as insects and spiders (Gutiérrez and Menendez 1998; Karl et al. 2008; Høye and Hammel 2010; and reviewed in Hodkinson 2005). Changes in body size associated with these clines are generally associated with developmental timing or local climate (Mousseau and Roff 1989; Chown and Klok 2003; Stillwell et al. 2007). Because the reproductive capacity of female arthropods is linked to body size (larger females produce larger clutches) and ultimately resource availability (Fox and Czesak 2000), one would expect changes along an elevational gradient to be reflected in fecundity as well.

Our research objectives were to first test whether there were body size differences between the sexes of three wolf spider species in low-Arctic Canada in response to changes in elevation. Since local density can influence body size relationships, we tested whether these changes were related to changes in local population density of the focal species. Our second objective was to test whether fecundity of female spiders changed with elevation independent of body size variation.

\section{Materials and methods}

From June 14 to July 26, 2006, ground-dwelling spiders were collected from mountains located along the Dempster Highway in the Yukon Territory, Canada. We sampled nine mountains in this region which ran along approximately $400 \mathrm{~km}$ from $64.309^{\circ} \mathrm{N}, 138.114^{\circ} \mathrm{W}$ to $66.725^{\circ} \mathrm{N}$, $136.114^{\circ} \mathrm{W}$. The elevations of the mountains ranged from 660 to 1460 meters. Spiders were collected by using six pitfall traps placed every 100 meters in elevation along an altitudinal transect on each mountain. Samples from each elevation on each transect on a mountain were treated as the unit of observation. Additional details about the pitfall trap methods, site descriptions (including map of the region), and community patterns are in Bowden and Buddle (2010a).

We selected three wolf spider (Araneae: Lycosidae) species as model taxa for addressing our research objectives. Pardosa lapponica (Thorell), P. uintana (Gertsch), and Alopecosa aculeata (Clerck) were all collected frequently at most of our study sites. This family represents the most dominant group of ground-dwelling spiders in the Arctic, and these species are the most dominant in the region (Bowden and Buddle 2010a, b). These species are also found across a broad range of elevations making them suitable candidates with which to statistically test intraspecific life history changes across a spatial gradient. We used $P$. lapponica collected from the southern-most and northern-most mountains (6 transects total), and $P$. uintana and $A$. aculeata collected from the south most and middle mountains ( 6 transects total) due to low sample sizes from other transects.

We used carapace width as a measure of body size (Foellmer and Moya-Laraño 2007). All adult males and females were measured, and the females' egg sacs dissected and contents counted using a Nikon ${ }^{\circledR}$ SMZ1000 stereoscopic microscope fitted with an ocular micrometer.

We tested for significant variation in male and female body size across elevation and whether local densities influenced the relationships. We used linear mixed models with elevation and each species' population density (measured as activity density) as numeric variables. We also tested for the main effect of sex and the interaction between elevation and sex. We used log-likelihood ratio 
tests to test for the significance of transect as a random effect using lme4 (Bates et al. 2011). We used linear models with body size as a covariate to test for variation in fecundity with elevation in $P$. lapponica and $P$. uintana independent of body size. We were unable to test for changes in fecundity with elevation for A. aculeata due to low sample size (see Table S2 for summary of fecundity data). All analyses were conducted using the $\mathrm{R}$ environment (R Development Core Team 2010) for windows with the base package.

\section{Results}

We collected 642 P. lapponica, 233 P. uintana, and 175 A. aculeata for analyses of body size and fecundity across the elevation gradient. Transect was not significant for any of the three species tested (Table S1). We found significant main effects of sex for $P$. lapponica and $P$. uintana (Table 1) with females being four percent and five percent larger, respectively; however, males and females of $A$. aculeata differed by less than one percent. We detected significant negative effects of elevation on body size for $P$. lapponica and $P$. uintana but there were not significant effects for A. aculeata (Table 1). Body size of P. uintana decreased significantly with increases in local density, but this relationship was not detected for the other two species (Table 1) and did not vary between the sexes for any species. We found a significant sex-elevation interaction for $P$. lapponica but not for $P$. uintana or A. aculeata (Table 1); the slopes for $P$. uintana males and females were very similar (Table 2). Body size varied significantly in response to elevation for each sex within each species with the exception of A. aculeata females (Table 2). Females of $P$. lapponica decreased more strongly with increases in elevation than did males, while males of A. aculeata responded positively to increases in elevation. Females of $P$. lapponica were significantly larger than males at lower elevations but this trend disappeared at higher elevations (Fig. 1).
Table 2 Summary statistics of simple linear regressions of body size (measured as carapace width) on elevation for each sex of each wolf spider species from the Yukon Territory, Canada

\begin{tabular}{lllllll}
\hline Species & Sex & $b$ & $F$ statistic & $d f$ & $p$ & $R_{\text {Adj }}^{2}$ \\
\hline P. lapponica & $\hat{\jmath}$ & $-7.45 \mathrm{E}-05$ & 10.07 & 1,434 & $* *$ & 0.02 \\
& + & $-2.63 \mathrm{E}-04$ & 24.25 & 1,204 & $* * *$ & 0.10 \\
P. uintana & $\hat{0}$ & $-2.34 \mathrm{E}-04$ & 32.27 & 1,116 & $* * *$ & 0.21 \\
& + & $-3.02 \mathrm{E}-04$ & 27.14 & 1,113 & $* * *$ & 0.19 \\
\multirow{4}{*}{ aculeata } & $\hat{\sigma}$ & $4.22 \mathrm{E}-04$ & 37.87 & 1,134 & $* * *$ & 0.22 \\
& + & $2.00 \mathrm{E}-04$ & 1.36 & 1,37 & $\mathrm{~ns}$ & 0.01 \\
\hline
\end{tabular}

ns Not significant

$* * p$ value $<0.01 ; * * * p$ value $<0.001$

The females of $P$. lapponica produced fewer progeny at higher elevations independent of body size variation (Estimate $=-0.014, p=0.005) . \quad P$. uintana did not exhibit a significant relationship with elevation; however, the two highest elevations at which gravid females were collected yielded the lowest number of eggs for this species (Table S2). Mean overall egg numbers for each species were $41.96 \pm 1.01$ eggs (mean $\pm \mathrm{SE}$ ) for $P$. lapponica, $40.92 \pm 1.22$ eggs for $P$. uintana, and $94.5 \pm 14.28$ eggs for A. aculeata.

\section{Discussion}

In this study based on the specimens from low-Arctic Canada, we found variation among the wolf spider species examined and in the case of $P$. lapponica, the sexes and populations across the elevational gradient. Høye and Hammel (2010) found similar results along a small-scale elevational gradient in three different wolf spider species in Greenland: males of two wolf spider species did not change in body size in response to changes in elevation but females declined significantly in size. This is in agreement with the hypothesis that female terrestrial arthropods are more plastic than males in response to environmental variation (reviewed in Stillwell et al. 2010) and supports the notion

Table 1 Summary statistics of linear models showing the effects of sex, elevation, and the focal species' density on body size (measured as carapace width) for each of the three wolf spider species collected in the Yukon Territory, Canada

\begin{tabular}{|c|c|c|c|c|c|c|c|c|c|c|c|c|c|c|c|}
\hline \multirow[t]{2}{*}{ Species } & \multirow[t]{2}{*}{$n$} & \multicolumn{2}{|l|}{ Intercept } & \multicolumn{2}{|l|}{ Sex } & \multicolumn{2}{|l|}{ Elevation } & \multicolumn{2}{|c|}{ Species' density } & \multicolumn{2}{|c|}{ Sex: elevation } & \multicolumn{4}{|l|}{ Model } \\
\hline & & Estimate & $p$ & Estimate & $p$ & Estimate & $p$ & Estimate & $p$ & Estimate & $p$ & $d f$ & $F$ statistic & $p$ & $R_{\mathrm{Adj}}^{2}$ \\
\hline $\begin{array}{l}P . \\
\quad \text { lapponica }\end{array}$ & 642 & 2.52 & $* * *$ & -0.322 & $* * *$ & $-2.87 \mathrm{E}-04$ & $* * *$ & $-5.68 \mathrm{E}-04$ & ns & $2.13 \mathrm{E}-04$ & $* * *$ & 4,616 & 32.76 & $* * *$ & 17.0 \\
\hline P. uintana & 233 & 2.49 & $* * *$ & -0.182 & $*$ & $-2.49 \mathrm{E}-04$ & $* * *$ & -0.0221 & $* *$ & $8.37 \mathrm{E}-05$ & ns & 4,228 & 32.34 & $* * *$ & 35.1 \\
\hline A. aculeata & 175 & 3.20 & $* * *$ & -0.280 & $\mathrm{~ns}$ & $2.52 \mathrm{E}-04$ & ns & -0.009 & $\mathrm{~ns}$ & 0.0002 & ns & 4,168 & 8.76 & $* * *$ & 15.3 \\
\hline
\end{tabular}

ns Not significant

$* p$ value $<0.05 ; * * p$ value $<0.01 ; * * * p$ value $<0.001$ 


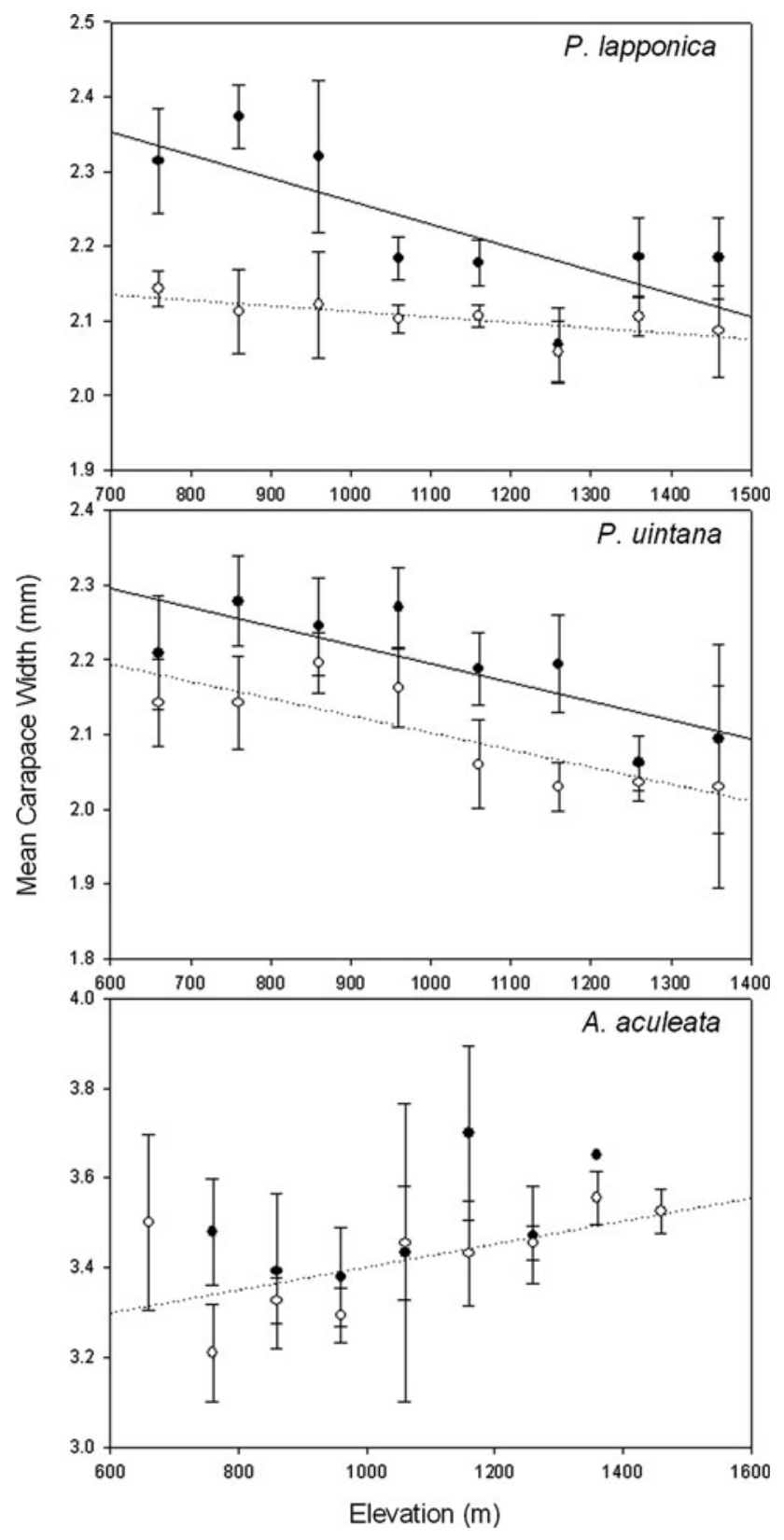

Fig. 1 Variation in body size in response to elevation for male (open dots) and female (closed dots) wolf spiders from the Yukon Territory, Canada. Mean body size (carapace width) and $95 \%$ confidence intervals are shown for each sex of each species across the elevational gradient. Regression lines are shown for all significant relationships $(p<0.05)$; males are shown by dotted lines and females by solid lines

that gender-specific life history responses to environmental variation may be taxonomically and geographically widespread among Arctic arthropods.

Although many hypotheses have been proposed to explain the causes of SSD in spiders (Foellmer and Moya-Laraño 2007), in general, male-biased SSD appears to arise from sexual selection (Stillwell et al. 2010) while fecundity selection supports larger females (Prenter et al. 1999;
Stillwell et al. 2010). However, SSD and selection for it can also be mediated by sex-specific differences in growth in response to external factors (Uhl et al. 2004; FernándezMontreveta and Moya-Laraño 2007; Stillwell and Davidowitz 2010; reviewed in Stillwell et al. 2010). Stillwell et al. (2010) show that physiological difference between the sexes in plasticity of growth rate and development time can be ultimately responsible for differences in adult body size.

One hypothesis regarding sexual selection keeping males small (e.g., protandry hypothesis) is that males sire more offspring the earlier they reach adulthood relaxing interference competition among males. Furthermore, scramble competition may select for a morphology that begets finding females more efficiently and earlier than other males (Foellmer and Moya-Laraño 2007), although this could also lead to larger males having an advantage (Foellmer and Fairbairn 2005).

Changes in density of these species across the elevational gradient could give way to density-dependent selection on body size patterns. We have uncovered some indication that density could be important in body size relationships of these Arctic species; however, although we statistically controlled for elevation, density is typically related to changes in elevation.

Another hypothesis is the sexual cannibalism hypothesis, which suggests that because sexual cannibalism is quite common in many spider species, smaller males are more agile and thus more able to avoid being eaten by females prior to copulation (Foellmer and Moya-Laraño 2007). Because sexual cannibalism increases with body size in spiders (Wilder and Rypstra 2008), it could especially have consequences for future climate-induced body size alterations that could yield changes in local dynamics of populations and communities (De Roos et al. 2003). There is, however, evidence that diet quality and/or quantity or other environmental factors (e.g., temperature), which change with elevation, can produce sex-specific and species-specific differences in body size plasticity (Stillwell and Davidowitz 2010; Stillwell et al. 2010). Furthermore, the degree to which genetics or phenotypic plasticity regulates patterns in SSD is poorly understood and the research is inconclusive (Stillwell and Fox 2009; Stillwell et al. 2010). Transplant experiments could help to determine the degree to which these factors influence SSD within and among species across gradients and, for example, our finding that males and females of $P$. uintana exhibited the same response in body size to changes in elevation. Due to the low sample sizes of A. aculeata females, it is difficult to infer size changes and patterns of SSD in this species, but this is one of the only species that displays significant increases in abundance with elevation in the region (Bowden and Buddle 2010a). One explanation for the differences in SSD between the genera is that phylogenetic differences among taxa affect the expression of SSD, 
possibly through differences in mating structure or trade-offs between growth and reproduction (Prenter et al. 1999).

Arthropods are predicted to display a decline in fecundity in response to increases in elevation (Hodkinson 2005) due to reductions in body size which is highly related to fecundity in female spiders (Simpson 1993; Buddle 2000; Bowden and Buddle 2012). We found significant effects of elevation on fecundity for $P$. lapponica independent of body size. Pardosa lapponica may have to invest more in maintenance during adulthood at higher elevations where resource availability is probably lower. We did not find a significant relation between elevation and fecundity for $P$. uintana but at the two highest elevations they exhibited the lowest fecundity so it is possible that these females are experiencing a similar effect, but only across large gradients in resource availability. The number of eggs produced by a given female, independent of body size, is often inversely related to the size of the individual offspring produced in Arctic dwelling wolf spiders (Simpson 1993; Bowden and Buddle 2012); lower fecundity at higher elevations could be explained by the production of larger offspring at higher elevations where resources are limiting (Roff 2002). This environmental constraint may naturally contribute to lower population sizes at higher elevations.

We have shown that life history traits (fecundity) and traits highly correlated with life history (body size) can vary significantly in response to environmental and biological factors across closely related species and between the sexes of individual species. These differences can be related to local population density, but in more extreme environments such as the Arctic, these patterns are more likely due to individual species or sex responses to environmental gradients. The forecasted changes in the Arctic environment (Callaghan et al. 2004; Hansen et al. 2006) are therefore likely to have profound effects on its fauna (e.g., Post et al. 2009). Our results provide additional evidence that arthropods will be particularly affected, although magnitudes of responses are species- and sex-specific.

Acknowledgments We would like to thank MW Foellmer for comments made on an early version of this manuscript. We would like to thank the Tetlit Gwitch'n, Nacho Nyak Dun, Vuntut Gwitch'n, Tr'ondëk Hwëch'in Han Nation and the Yukon Territorial Government. The authors would also like to thank Dan Brown for help with collection of specimens in the field. Financial support was provided by the Northern Scientific Training Program, the National Science and Engineering Research Council of Canada, and McGill University.

\section{References}

Bates D, Maechler M, Bolker B (2011) lme4: linear mixed-effects models using S4 classes. R package version 0.999375-42. http://CRAN.R-project.org/package=lme4
Blanckenhorn WU, Demont M (2004) Bergmann and converse Bergmann latitudinal clines in arthropods: two ends of a continuum? Integr Comp Biol 44:413-424

Blanckenhorn WU, Stillwell RC, Young KA, Fox CW, Ashton KG (2006) When Rensch meets Bergmann: does sexual size dimorphism change systematically with latitude? Evolution 60:2004-2011

Bowden JJ, Buddle CM (2010a) Spider assemblages across elevational and latitudinal gradients in the Yukon Territory, Canada. Arctic 63:26-272

Bowden JJ, Buddle CM (2010b) Determinants of ground-dwelling spider assemblages at a regional scale in the Yukon Territory, Canada. Écoscience 17:287-297

Bowden JJ, Buddle CM (2012) Life history of tundra-dwelling wolf spiders (Araneae: Lycosidae) from the Yukon Territory, Canada. Can J Zool 90:714-721

Buddle CM (2000) Life history of Pardosa moesta and Pardosa mackenziana (Araneae, Lycosidae) in central Alberta, Canada. J Arachnol 28:319-328

Callaghan TV, Bjorn LO, Chernov Y et al (2004) Effects on the structure of arctic ecosystems in the short- and long-term perspectives. Ambio 33:436-447

Chown SL, Klok CJ (2003) Altitudinal body size clines: latitudinal effects associated with changing seasonality. Ecography 26:445-455

De Roos AM, Persson L, McCauley E (2003) The influence of sizedependent life-history traits on the structure and dynamics of populations and communities. Ecol Lett 6:473-487

Fairbairn DJ (2007) Introduction: the enigma of sexual size dimorphism. In: Fairbairn DJ et al (eds) Sex, size and gender roles: evolutionary studies of sexual size dimorphism. Oxford University Press Inc., New York, pp 1-10

Fernández-Montreveta C, Moya-Laraño J (2007) Sex-specific plasticity of growth and maturation size in a spider: implications for sexual size dimorphism. J Evol Biol 20:1689-1699

Foellmer MW, Fairbairn DJ (2005) Selection on male size, leg length and condition during mate search in sexually highly dimorphic orb-weaving spider. Oecologia 142:653-662

Foellmer MW, Moya-Laraño J (2007) Sexual size dimorphism in spiders: patterns and processes. In: Fairbairn DJ et al (eds) Sex, Size and Gender Roles: Evolutionary Studies of Sexual Size Dimorphism. Oxford University Press, Oxford, pp 71-81

Fox CW, Czesak ME (2000) Evolutionary ecology of progeny size in arthropods. Annu Rev Entomol 45:341-369

Gutiérrez D, Menendez R (1998) Phenology of butterflies along an altitudinal gradient in northern Spain. J Zool 244:249-264

Hansen J, Sato M, Ruedy R, Lo K, Lea DW, Medina-Elizade M (2006) Global temperature change. Proc Natl Acad Sci USA 103:14288-14293

Hodkinson ID (2005) Terrestrial insects along elevation gradients: species and community responses to altitude. Biol Rev 80: 489-513

Høye TT, Forchhammer MC (2008) Phenology of high-arctic arthropods: effects of climate on spatial, seasonal and interannual variation. Adv Ecol Res 40:299-324

Høye TT, Hammel JU (2010) Climate change and altitudinal variation in sexual size dimorphism of arctic wolf spiders. Clim Res 41:259-265

Høye TT, Post E, Meltofte H, Schmidt NM, Forchhammer MC (2007) Rapid advancement of spring in the High Arctic. Curr Biol 17:R449-R451

Høye TT, Hammel JU, Fuchs T, Toft S (2009) Climate change and sexual size dimorphism in an Arctic spider. Biol Lett 5:542-544

Karl I, Janowitz SA, Fischer K (2008) Altitudinal life-history variation and thermal adaptation in the copper butterfly Lycaena tityrus. Oikos 117:778-788 
Mousseau TA, Roff DA (1989) Adaptation to seasonality in a cricket - patterns of phenotypic and genotypic variation in body size and diapause expression along a cline in season length. Evolution 43:1483-1496

Post E, Forchhammer MC, Bret-Harte MS et al (2009) Ecological dyanmics across the Arctic associated with recent cllimate change. Science 325:1355-1358

Prenter J, Elwood RW, Montgomery WI (1999) Sexual size dimorphism and reproductive investment by female spiders: a comparative analysis. Evolution 53:1987-1994

R Development Core Team (2012) R: a language and environment for statistical computing. R Foundation for Statistical Computing, Vienna, Austria. ISBN 3-900051-07-0, http://www.R-project. org/

Roff DA (2002) Life history evolution. Sinauer Associates, Sunderland, MA

Schäuble CS (2004) Variation in body size and sexual dimorphism across geographical and environmental space in the frogs Limnodynastes tasmaniensis and L-peronii. Biol J Linn Soc 82:39-56

Simpson MR (1993) Reproduction in two species of arctic arachnids, Pardosa glacialis and Alopecosa hirtipes. Can J Zool 71: 451-457

Stillwell RC, Davidowitz G (2010) A developmental perspective on the evolution of sexual size dimorphism of a moth. Proc R Soc B Biol Sci 277:2069-2074

Stillwell RC, Fox CW (2007) Environmental effects on sexual size dimorphism of a seed-feeding beetle. Oecologia 153:273-280
Stillwell RC, Fox CW (2009) Geographic variation in body size, sexual size dimorphism and fitness components of a seed beetle: local adaptation versus phenotypic plasticity. Oikos 118:703-712

Stillwell RC, Morse GE, Fox CW (2007) Geographic variation in body size and sexual size dimorphism of a seed-feeding beetle. Am Nat 170:358-369

Stillwell RC, Blanckenhorn WU, Teder T, Davidowitz G, Fox CW (2010) Sex differences in phenotypic plasticity affect variation in sexual size dimorphism in insects: from physiology to evolution. Annu Rev Entomol 55:227-245

Tulp I, Schekkerman H (2008) Has prey availability for Arctic birds advanced with climate change? Hindcasting the abundance of tundra arthropods using weather and seasonal variations. Arctic 61:48-60

Uhl G, Schmitt S, Schafer MA, Blanckenhorn W (2004) Food and sex-specific growth strategies in a spider. Evol Ecol Res 6: $523-540$

Wilder SM, Rypstra AL (2008) Sexual size dimorphism predicts the frequency of sexual cannibalism within and among species of spiders. Am Nat 172:431-440 